\title{
As arranhaduras da masculinidade: uma discussão sobre o toque retal como medida de prevenção do câncer prostático
}

\author{
The touched masculinity: a discussion about the digital rectal \\ exam for prostate cancer prevention
}

\author{
Romeu Gomes ${ }^{1}$ \\ Elaine Ferreira do $\mathrm{N}$ ascimento ${ }^{1}$ \\ Lúcia Emília Figueiredo deSousa Rebello ${ }^{1}$ \\ Fábio Carvalho deAraújo ${ }^{1}$
}

\footnotetext{
${ }^{1}$ Departamento deEnsino, Instituto Fernandes Figueira, Fundação Oswaldo Cruz. Av. Rui Barbosa 716, Flamengo. 22250-020 Rio deJaneiro RJ.romeu@iff.fiocruz.br.
}

Abstract The present study aims at analyzing the meaningsattributed to the digital rectal exam, seeking to problematizequestionsunderlying the masculinediscourse on the basis of aspects of the hegemonic masculinity model. Semi-structured interviews were held with 28 men in the city of Rio de Janeiro, in 2004. Among the main results is the idea that the digital rectal exam is something that violates an interdicted space, something that compromises the current understanding of masculinity, shall say, the digital rectal exam does not only affect the prostate, it also affects the masculinity, puts it to shame. We conclude that for understanding and problematizing the questions related to the prostate cancer prevention in special, and to the question of taking care of oneself from themasculine perspective in general, we need to consider the structural and symbolic aspects that underlie these questions.

Key words Prostrate cancer, Prevention, Digital rectal exam, M asculinity
Resumo 0 presenteestudo tem por objetivo analisar os sentidos atribuídos ao toque retal, buscando refletir acerca de questões subjacentes a falas masculinas a partir de aspectos do model o hegemônico de masculinidade. 0 método do estudo baseia-senuma abordagem de pesquisa qualitativa, através de entrevistas semi-estruturadas, com 28 homens, realizadas na cidade do Rio de Janeiro, em 2004. Dentre os principais resultados, destaca-sea idéia de que o exame do toque retal pode suscitar interdições e violações, podendo ser percebi do como algo que compromete o que se entende comumente por ser homem; ou seja, o toque retal não toca apenas a próstata, mas também toca na masculinidade, podendo arranhá-la. Concluiseque, para a compreensão e problematização das questões sobre a prevenção do câncer prostático, em específico, e as relacionadas ao cuidar de si masculino, em geral, se faz necessário levar em consideração os aspectos estruturais e simbólicos que perpassam tais questões.

Palavras-chave Câncer de próstata, Prevenção, Toque retal, M asculinidade 
Introdução

0 câncer de próstata é o tipo de neoplasia mais preval enteem homens, com estimativa de $1,5 \mathrm{mi}$ Ihões com diagnósticos nos últimos anos ${ }^{1}$. Um em cada seis homens, com idade de 45 anos, pode ter a doença sem que nem sequer saiba disso ${ }^{2}$, possivelmente pelo fato deste tipo de doença, muitas vezes, se desenvolver de forma assintomática, induzindo os homens à crença de que, se não apresentam sintomas, é porque não estão doentes.

$\mathrm{Na}$ literatura médica sobre o assunto, é re corrente a idéia de queo câncer de próstata pode ser detectado precocemente através de métodos detriagem ${ }^{3}$ e queo diagnóstico precoce da doença éa única maneira de evitar e reduzir a mortalidade deste tipo de câncer ${ }^{4}$.

0 Instituto Nacional deCâncer (INCA $)^{5}$ procura regular a detecção precocedo câncer depróstata, apresentan do recomen dações que surgiram a partir de consensos. N esse sentido, recomenda que seja realizado o rastreamento oportunístico (case finding), ou seja, a sensibilização de homens com idade entre 50 e 70 anos que procuram os serviços de saúde por motivos outros que não 0 câncer da próstata sobre a possibilidade de detecção precoce deste câncer [...]" $]^{5}$.

A Sociedade Brasileira de U rologia (SBU) ${ }^{6}$, por sua vez, recomenda que os homens que têm acima de 50 anos e os que têm 40 anos, com histórico familiar de câncer de próstata, pensem na possibilidade de "ir anualmente ao urologista para fazer check-up da próstata", mesmo que não tenha sintomas urinários.

Em termos de diagnóstico precoce do câncer de próstata, costuma-se recomendar o exameclínico (toque retal ou toque digital da próstata) e o exame de sangue para a dosagem do antígeno prostático específico, conhecido por PSA, sigla inglesa da expressão prostatic specific antigen, informando-se sobre as limitações, os benefícios e os riscos da detecção precoce do câncer de próstata 5 .

Essa recomendação tem apoio na literatura médica internacional. Uma revisão literária sistemática ${ }^{7}$ de artigos publicados e indexados pela M edlinee Pubmed, no período 1966 a 2003, concluiu que o valor sérico do PSA associado ao toque retal é o método de maior sucesso no diagnóstico do câncer prostático.

Entretanto, tal recomendação é polemizada por inúmeros estudos. Walsh e Worthington ${ }^{8}$, por exemplo, questionam o toque retal, afirmando quemuitoshomens quando têm o câncer pros- tático detectado por esse exame já se encontram em estado avançado da doença. Já Shimizu ${ }^{9}$ traz o posicionamento de Thomas Stamey da Universidade de Stanford (Estados Unidos), que coloca em xeque o PSA, afirmando que tal exame tem seus dias contados. Stamey foi um dos primeiros a defender esse exame, mas atualmente- baseado em pesquisa por ele liderada e em outros estudos - questiona tanto a sua eficácia quanto a necessidade de ser utilizado o PSA, defendendo o toque retal ainda como a melhor solução.

Em se tratando da realização do toque retal como medida preventiva secundária do câncer prostático, independentemente da polêmica quanto a sua eficácia, a discussão não pode desconsiderar aspectos simbólicos que interferem diretamente na decisão de realizar exame/diagnóstico, criando barreiras para a maioria dos homens, uma vez que o toque retal podeser visto como uma violação ou um comprometimento da masculinidade ${ }^{4,10}$. Tanto na clínica - no âmbito das relações de escuta e tratamento - como na Saúde Coletiva - no campo da prevenção da doença e da elaboração de políticas de assistência à saúde do homem - essas questões não se encontram suficientementedebatidas, demandando um maior investimento nessa discussão.

A partir dessa perspectiva, no presente estudo, pretendemos analisar os sentidos atribuídos ao toque retal por parte dos homens, procurando problematizar questões subjacentes às falas masculinas a partir de aspectos do modelo hegemônico de masculinidade.

A masculinidade, numa perspectiva relacional de gênero, pode ser vista como um espaço simbólico que serve para estruturar a identidade de ser homem, através de prescrições a serem seguidas por aqueles que desejam receber 0 atestado de masculinidade e não sejam questionados e nem objetos de estigma por parte daqueles que compartilham dessas prescrições ${ }^{11}$. Dentre os "diversos modelos de masculinidade disponíveis, al guns são mais valorizados e exaltados, enquanto outros são desprezados e subordinados, no mesmo contexto" 12.

$\mathrm{Na}$ relação entre os diferentes modelos de masculinidade, aquele que consegue ser mais valorizado, com maior legitimidade, e se apropriar de outros modelos, concentrando maior poder, pode ser considerado hegemônico. Tal modelo, ideal mente formulado e dificilmente seguido por todos os homens, consiste numa referência que, ao mesmo tempo, se impõee se relaciona com os modelos alternativos ou subordinados. No modelo da masculinidade hegemônica, destacam-se 
como eixos estruturantes a dominação e a heterossexualidade.

\section{Desenho metodológico}

Nosso estudo é parte de uma investigação que procurou problematizar aspectos relacionados ao modelo hegemônico da masculinidade que podem impedir homens de cuidar de sua própria saúde, realizada na cidade do Rio de Janeiro, em 2004. Essa investigação pautou-senuma abordagem de pesquisa qualitativa, aqui entendida como um conjunto depráticas interpretativas que busca investigar os sentidos que os sujeitos atribuem aos fenômenos e ao conjunto de relações em que eles se inserem ${ }^{13}$ 14. N essa abordagem, baseados em princípios da hermenêutica-dialé tica ${ }^{15}$, procuramos compreender e contextualizar os sentidos subjacentes às falas dos sujeitos investigados.

Os sujeitos do estudo foram selecionados a partir de uma prática bastante usual em pesquisa social sobre os universos familiares ${ }^{16,17}$, em que pessoas conhecidas do pesquisador indicam outras a serem entrevistadas, que, por sua vez, indicam outras conhecidas. Ao longo da pesquisa, nem semprefoi possível contar com a indicação de uma pessoa conhecida dos entrevistados, fazendo com que novas cadeias de informantes fossem iniciadas.

A amostra de conveniência foi composta a partir dos seguintes princípios: (a) escolher os sujeitos que detém os atributos relacionados ao que se pretende estudar (no caso deste trabalho, homens a partir de 40 anos - foco da prevenção de câncer de próstata - residentes ou que trabaIhem na cidade do Rio deJ aneiro, emédicos com experiência de trabalho relacionada ao câncer de próstata de, no mínimo dois anos); (b) considerar tais sujeitos em número suficiente para que possa ter uma certa reincidência das informações; (c) levar em conta a possibilidade de inclusões sucessivas de sujeitos até que seja possível uma discussão densa das questões da pesquisa. Assim, a amostra não buscou uma representatividade numérica e sim um aprofundamento da temática ${ }^{18}$.

A coleta dos dados se apoiou em entrevistas semi-estruturadas, realizadas em horários e locais escolhidos pelos entrevistados, em um único encontro, durando em média 1h30min. Nesse tipo de coleta, procuramos estabelecer uma conversa dirigida com os entrevistados em torno de temas que integravam o objeto da pesquisa. No caso desterecorte da pesquisa, focalizamos questões relacionadas aos cuidados da saúde do homem, à prevenção do câncer de próstata em geral e ao toque retal em específico.

Em termos de procedimento analítico adotado no trato dos depoimentos, neste estudo utilizamos o método de interpretação de sentidos ${ }^{19}$, com base em princípios hermenêuticos-dialéticos para a interpretação do contexto, das razões e das lógicas dos depoimentos que giraram em torno das temáticas do estudo.

Natrajetória analítico-interpretativa, percorremos os seguintes passos: (a) leitura compreensiva, visando impregnação, visão de conjunto e apreensão das particularidades do material gerado pela pesquisa original; (b) identificação e recorte temático dos depoimentos sobre a realização do toque retal como medida de prevenção secundária para o câncer prostático; (c) identificação e problematização das idéias explícitas e implícitas no texto; (d) busca de sentidos mais amplos (socioculturais) que articulam as falas dos sujeitos da pesquisa; (e) diálogo entre as idéias problematizadas, informações provenientes de outros estudos acerca do assunto e o referencial teórico do estudo; e (f) elaboração de síntese interpretativa, procurando articular objetivo do estudo, base teórica adotada e dados empíricos.

0 projeto de pesquisa da qual se insere este trabalho foi avaliado pelo Comitê de Ética em Pesquisa com Seres Humanos do Instituto Fernandes Figueira/Fiocruz, em cumprimento da resolução n 196/96 do Conselho Nacional de Saúde. Para garantir o caráter sigiloso das informações, os depoimentos dos entrevistados foram codificados com nomes fictícios iniciados pela letra " $A$ " para os homens do Grupo I, com a letra "M " para os do Grupo II e com a letra "D" para os médicos.

\section{Caracterização dos sujeitos do estudo}

Com base em critérios de amostra de conveniência, entrevistamos dezoito homens que moravam ou trabalhavam na cidade do Rio de Janeiro, que foram agrupados da seguinte forma: Grupo I: homens de baixa ou nenhuma escolaridade; Grupo II: homens de nível superior. Essa organização se deu para se problematizar possíveis influências do grau de instrução no que se refere a ações preventivas do câncer de próstata. Além desses sujeitos, foram ouvidos dez médicos para que pudéssemos estabelecer um diálogo de suas falas com as dos outros dois grupos. 
O Grupo I foi composto por dez homens com idades entre 45 e 57 anos. Seus integrantes se autodeclararam, em sua maioria, pardos (7). Os demais se autodeclararam branco (1), preto (1) e amarelo (1). Nove deles cursaram até a quarta série do ensino fundamental eum respondeu não ter nenhuma instrução. Entre eles, nove eram casados e um afirmou ser solteiro. A renda mensal dos entrevistados apresentou uma média de 3,3 salários mínimos, sendo que o menor rendimento foi de um salário mínimo e o maior de oito salários mínimos. $\mathrm{Na}$ época da coleta das informações, em 2004, o salário mínimo do estado do Rio de Janeiro era de $R \$ 305,00$. Entre as atividades exercidas, destacaram-se as de carpinteiro, pintor e armador, além de ascensorista, mestre de serviços operacionais, pedreiro e servente. A maioria deles residia em municípios vizinhos à cidade do Rio de Janeiro.

O Grupo II foi composto por oito homens. Os entrevistados tinham entre 40 e 64 anos e se autodeclararam brancos (4), pretos (2) e pardos (2). Em relação ao estado civil, quatro eram casados e quatro solteiros. A renda mensal dos entrevistados apresentou uma média aproximada de quinze salários mínimos, sendo que o me nor rendimento foi de oito e o maior de vinte salários mínimos. Entre as atividades exercidas, foram verificadas as profissões de professor, psicólogo, engenheiro, advogado e economista. Todos residiam na cidade do Rio de Janeiro.

Entre os médicos entrevistados, cuja caracterização contemplou apenas o tempo de experiência e formação acadêmica, um estava envolvido com a prevenção do câncer de próstata (atuando no INCA) e nove eram especialistas ou residentes em urologia. A média deidade do grupo era de 44 anos, sendo que sete encontravam-se na faixa entre 40 e 55 anos e três na faixa entre 25 e 30 anos. Quanto ao tempo de experiência no campo específico do câncer de próstata, cinco tinham mais de vinte anos de experiência e cinco menos de três anos de experiência profissional. 0 médico com maior tempo deexperiência(trinta anos) tinha como maior titulação o mestrado; no entanto, a maioria dos entrevistados (6) tinha como maior título a residência médica. $\mathrm{Ou}$ tro dado interessante na caracterização dos mé dicos é que o com maior titulo acadêmico (doutorado) era o que tinha menor experiência no tratamento e prevenção do câncer de próstata (dois anos).
O cenário da detecção precoce do câncer de próstata

Antes deiniciarmos a discussão dos aspectossimbólicos relacionados à realização do toque retal como detecção precoce - aqui entendida como prevenção secundária - do câncer prostático, é necessário apontarmos aspectos relacionados ao contexto em que tal discussão se insere. Inúmeras questões, tangenciadas pelos aspectos simbólicos relacionados a problemas de busca masculina por cuidados em saúde e ao câncer em geral, compõem o cenário dessa discussão. Tais questões - se negligenciadas - podem comprometer a produção de um conhecimento necessário para que se possa agir frente aos problemas suscitados pelo toque retal.

Caminhando nessa direção, observamos que não estamos tratando de uma prevenção qualquer. Estamos falando de ações que, de uma forma ou outra, mexem com sentimentos que surgem a partir da representação do câncer como um mal, visto no senso comum como fatal. Independente de ser homem ou mulher, as pessoas - quando são acometidas por esses sentimentos - podem ser impedidas de buscar diagnósticos que precocemente detectem tal doença e contribuam para um efetivo tratamento. Historicamente 0 câncer vem sendo associado a experiências malditas e servindo como metáforas para diversas ordens de infortúnios físicos, mentais e sociais. Freqüentemente somos lembrados dos diferentes tipos de "cânceres" sociais. A violência, a desintegração familiar, o uso de drogas ea corrupção têm sido referidos como perturbadores da ordem e, conseqüentemente, denominados câncer ${ }^{10}$.

Em nosso estudo, transversalmente a todos os fatores que dificultam a realização do toque retal, está presente o medo dos homens buscarem um diagnóstico precoce para o câncer prostático, gerado pela associação de câncer à morte. Como diz um dos médicos entrevistados:

0 câncer no coletivo social está muito ligado à morte. É comum as pessoas falarem 'aquela doença' e isso certamente mexe muito com a busca do diagnóstico . (Damião)

0 fato de sefalar de uma doença, queàs vezes nem o nome se pronuncia, pode comprometer a busca de um diagnóstico a ela relacionada. A idéia do que não é pronunciado pode ter influenciado alguns dos nossos entrevistados quando falam:

[Dependendo] dos exames [o homem] tem aquela cisma, aquele medo". (Adalberto)

Eu acho que tem um temor terrível de encarar qualquer possibilidadedequealgo vai mal. (Murilo) 
Não podemos descartar a possibilidade de "aquela cisma" e "algo vai mal" estarem no lugar do câncer como algo que não se pronuncia.

A não busca de medidas preventivas do câncer de próstata também pode ser influenciada por aspectos culturais que refletem na socialização dos homens em geral. Segundo um dos entrevistados, o homem não se interessa de se cuidar mesmo da saúde. Já a mulher, ela se interessa. A mulher se cuida mais do que o homem. (Almir)

A possível indiferença em relação ao cuidar de si por parte dos homens pode ser explicada a partir da perspectiva da construção social. Segundo essa perspectiva, mulheres e homens pensam e agem de maneira diferenciada porque são influenciados pela construção de uma feminilidade e masculinidade ditada por sua cultura, ou seja, os indivíduos são estimulados a adaptar-se a estereótipos que os leva a assumir normas dominantes de feminino e masculino ${ }^{20}$. Tais normas, culturalmente construídas, podem suscitar sentimentos e comportamentos que se diferenciam por gênero.

A necessidade de responder a uma norma de masculinidade também afeta a solicitação, por parte dos homens, de atenção aos serviços de saúde. Para o homem, é muito difícil ocupar o papel de pacientee, com freqüência, nega a possibilidade de estar enfermo e procura um médico, só em último caso, já que ao contrário poderia estar assumindo um papel passivo, dependentee de fragilidade ${ }^{21}$.

Junto aos aspectos simbólicos que interferem na busca de cuidados de saúde em geral por parte dos homens, há outras questões de ordem mais estrutural que também podem impedir tal busca. N esse sentido, as falas dos nossos entrevistados apontam para: (a) dificuldades em se conciliar 0 atendimento dos serviços de saúde com as jornadas de trabalho dos homens que necessitam dos serviços públicos; (b) falta de recursos financeiros para se conseguir um atendimento privado ou para se ter acesso a exames complementares; (c) precarização dos serviços públicos em atender às demandas de cuidados em saúde da população em geral. Ilustram esses aspectos os seguintes depoimentos:

Pra pessoa cuidar da saúdetem quematar aquele dia. Aí fica difícil pra gente que trabalha, não tem um tempo suficiente. (Alberto)

[Existe a dificuldade de se ter] acesso ao sistema de saúde, mesmo aqui no hospital no ponto de vista preventivo a gente ainda fica muito limitado porque a demanda é muito grande. (Diogo).

Essas questões apontadas pelos nossos sujei- tos não se relacionam apenas às especificidades de segmentos masculinos, mas também podem ser fatores impeditivos para a população em geral, principalmente no que se refere aos grupos economicamente mais desfavorecidos.

Entretanto, as condições estruturais não podem ofuscar a coexistência de outros problemas, de ordem mais simbólica, que fazem com que os homens não procurem medidas preventivas do câncer prostático nos serviços de saúde, sejam eles públicos ou privados. Isso pode ser melhor discutido quando olhamos para alguns dos homens entrevistados do Grupo II que, embora tenham melhor nível socioeconômico e jornadas de trabalho mais flexíveis do que os homens do Grupo I, também não buscam serviços de saúde e pouco ou nada se cuidam. As falas de alguns médicos também ilustram essa situação quando dizem que eles próprios não buscam os cuidados de saúde.

Outro aspecto que compõe o cenário da nossa discussão se relaciona a questões de informações e escolaridade. Entre os médicos entrevistados por nós, há um pressuposto de que a informação pode influenciar na decisão dos homens, tanto em relação ao autocuidado em geral como também em relação à prevenção do câncer de próstata, principalmente no que diz respeito a realizar o toque retal.

Ilustrando esse posicionamento, destacamos a fala de um urologista: 0 cara que vem aqui no consultório, ele vem porque precisa vir. Ele vence barreiras. M as essas barreiras existem. Ele consegue vencer as barreiras porque ele [tem] informação. (D ouglas)

No que se refere à realização do exame de toqueretal, entre os nossos entrevistados, aparentemente, o grau de escolaridade pode se relacionar a tal decisão. Entre os dez entrevistados de baixa ou nenhuma escolaridade (Grupo I), observamos que nove responderam que não havia feito 0 exame, mesmo estando na faixa etária onde é recomendado que se faça. Já em relação aos oito entrevistados com nível superior (Grupo II), cinco afirmaram ter realizado o exame do toque retal.

Esses números, entretanto, necessariamente não são indicativos de uma associação entre grau de escolaridade, informação e realização do toqueretal. A facilidade deter acesso aosserviços de saúde, por exemplo, podeser outro fator quecontribui para a realização de tal exame. Por outro lado, o nosso interesse não é discutir o quanto de homens faz exames preventivos e quais fatores interferem nesse quantitativo. Se fosse esse o nosso interesse, não trabalharíamos com uma amos- 
tra de conveniência e sim com um desenho de estudo randomizado. Interessa-nos discutir os sentidos atribuídos ao toque retal e à prevenção do câncer prostático em geral para os homens.

Segundo Lucumi-Cuesta e Cabrera-Arana22, a falta de informação sobre a prevenção ou sobre o tratamento do câncer de próstata pode estar relacionada a baixos níveis de escolaridade. Eles concluíram que a desinformação atinge com maior intensidade a população masculina com menor nível de escolaridadee poder socioeconômico, demandando ações educativas voltadas, principalmente, para este grupo.

De acordo com $\mathrm{N}$ ascimento ${ }^{4}$, a escolaridade, associada à idade, é um elemento significativo para a realização do exame do toque retal. Segundo o autor, homens - mais novos e com maior escolaridade - disseram não ter muitas restrições para realizar o exame de toque retal apesar de que, em alguns casos, teriam hesitado em realizá-lo. Já homens mais velhos ecom pouca escolaridade teriam mencionado não ter realizado o exame, pois não teriam apresentado sintomas, o que revelaria, "conhecimento fragmentado da doença, não a associando à idade" ${ }^{4}$.

Por outro lado, na própria literatura médica sobre 0 assunto, observamos sólidos argumentos de que nem sempre a informação resulta em prevenção. M iranda e colaboradores ${ }^{3}$, por exemplo, concluíram que $20,7 \%$ dos professores-mé dicos de uma universidade estudados, mesmo tendo acesso fácil à informação e aos serviços de diagnóstico clínico e complementar, nunca realizaram práticas preventivas para o câncer de próstata. Assim, o acesso à informação pode ser um caminho para a prática preventiva, porém não justifica, por si só, a não realização desta.

$N$ ão temos a intenção de saber se os homens que se previnem contra o câncer prostático são ou não influenciados pela informação e o seu grau deescolaridade. N esteestudo, inter essa-nos compreender os sentidos atribuídos ao toque retal como medida preventiva do câncer depróstata e se esses sentidos se diferenciam ou não a partir do grau de escolaridade. Essa discussão será retomada por nós na parte final da interpretação dos achados do nosso estudo.

Abordar esses e outros aspectos, aqui apontados como cenário da detecção precoce do câncer de próstata, é de fundamental importância para a busca de medidas preventivas mais efetivas. No entanto, neste estudo, recortamos como foco de discussão as questões si mbólicas presentes nas falas dos sujeitos no que se refere à realização do toque retal. Nesse sentido, subjacente às dificuldades masculinas, nós procuraremos problematizar a influência do modelo hegemônico de masculinidade, socialmente construído, presente nos sentidos atribuídos a esse exame.

\section{O toquena masculinidade}

0 toque retal não pode ser visto apenas como um exame físico que pode diagnosticar precocemente o câncer de próstata. Esse examenão toca apenas na próstata. Ele toca em aspectos simbólicos do ser masculino que, se não trabalhados, podem não só inviabilizar essa medida de prevenção secundária como também a atenção à saúde do homem em geral. Com base na interpretação das falas dos nossos entrevistados, podemos dizer que, mais do que na próstata, o toque retal toca na masculinidade.

Seguindo na direção dessa discussão, de início, observamos que os homens dos Grupos I e II ancoraram suas opiniões em relação ao toque retal em idéias do modelo hegemônico de masculinidade. N essesentido, independentementedo nível de escolaridade, os entrevistados lançaram mão das seguintes idéias do que é ser homem: "bruto", "forte", "agressivo", "tem iniciativa sexual (ativo)", "vive mais na rua" e "gosta de pular a cerca (é sexual menteinfiel)". O fato deterem utilizado tais idéias para compor suas falas não significa que necessariamente com elas concordavam. Uns as utilizavam quase que como "verdades", enquanto outros faziam críticas sobre elas. Num e noutro caso, podemos dizer que essas idéias compunham o imaginário dos entrevistados, sendo subjetivadas de formas diferenciadas.

Essas idéias do queé ser homem - reflexos de aspectos do model o de masculinidade hegemônica - serviram de referência para os entrevistados atribuírem sentidos à realização do toque retal. Esses sentidos, que não se excluem mutuamente, assim como as idéias de ser homem, não variaram pelo grau de escolaridade dos entrevistados. Foram utilizados com ou sem crítica tanto pelos homens do Grupo I como os do Grupo II.

0 primeiro sentido atribuído ao toque retal foi o de invasão de um espaço interdito do corpo masculino:

[Para um homem] já é difícil que um outro homem introduza o dedo no seu ânus. (Damião)

$\mathrm{N}$ ão mesinto bem à vontade de alguém chegar edar um toque em mim ali no lugar [se referindo ao ânus]. (Adalberto)

Tudo que diga respei to a examinar o ânus fica um pouco mais difícil. (M arcos) 
Estudo qualitativo realizado na Colômbia com homens de vários estratos sociais, de uma certa forma, reforça a idéia de espaço interdito, uma vez que, dentre os seus achados acerca do efeito do toque retal sobre a masculinidade, concluiu que para alguns homens a zona anal masculina é percebida como uma parteque não deve ser explorada ${ }^{23}$.

As falas dos nossos sujeitos sobre partes interditas dos homens nos remetem a questões culturais mais amplas acerca da construção do corpo no espaço relacional de gênero. A construção do corpo masculino "ideal" envolve, antes de tudo, a idéia de oposição complementar do corpo feminino ${ }^{24}$. Essa oposição não se dá pela parte traseira do corpo. 0 traseiro - com o seu orifício como parte macia, semi-aberta e frágil - se associa à parte mais feminina do corpo masculino ${ }^{25}$; enquanto a parte dianteira diferencia o homem da mulher, a parte traseira a ela o iguala. Se o pênis éuma marca do ser homem, a nádega éo outro lado da medalha. N esse sentido, tocar nessa parte "inferior" pode comprometer a masculinidade de quem se deixa tocar ${ }^{23}$ e, portanto, 0 homem se sentehumilhado em ter que fazer o exame físico (Diogo).

A interdição de partes do corpo reflete que culturalmentehá uma regulação do quepodeser mostrado e o que não deve ser mostrado. Como diz um dos entrevistados: eu me sinto constrangido. A gente mostra a língua, mas não pode mostrar o [ânus], não é? Eu acho queisso étabu (M árcio). Essa fala revela uma lógica de que, quando sepercorrelugaresinterditos, o mínimo quepode ocorrer é haver um constrangimento, ainda que se faça uma crítica à interdição.

Se o simples fato de tocar nas nádegas pode indicar que uma parteinterdita do corpo masculino está sendo invadida, o toque retal podesimbolicamenteser visto como uma violação da masculinidade, uma vez que se associa à penetração sexual. As falas dos nossos entrevistados são bastante ilustrativas:

Eu acho que[oshomens em geral] devem pensar, entre aspas, que estão sendo violentados, mas isso não se encaixa na minha cabeça. (M ilton).

$\mathrm{N}$ ão vai me enfiar o dedo porque eu sou macho, compadre. Essa mentalidade afasta o homem, acho que o homem associa à penetração. (M ário)

Sexo anal, que eu acho que é o que acabam associando ao toque retal. (D amião)

0 fato de ter que ser penetrado pode fazer com que os homens expressem constrangimentos e resistências, uma vez que a imagem do masculino se associa ao penetrador (ativo) enão ao ser penetrado (passivo). Assim, a condição de ser passivo no momento do exame poderia conspirar contra o modelo vigente de ser masculino 4.

Ampliando a discussão, o toque retal pode suscitar nos sentimentos mais recônditos dos homens a inversão do masculino. Ser passivo se associa ao ser penetrado, ao ser "comido". M etaforicamente, são as mulheres e os "veados" que são "comidos" pelos homens ${ }^{25}$.

A partir dessa reflexão, o toque retal pode não ser visto apenas como uma penetração física. Tal exame, simbolicamente, pode ser associado à violação do ser masculino via penetração. Por isso, ninguém vai "meenfiar o dedo porqueeu sou macho".

A associação do toque retal à violação da masculinidadetambém foi encontrada por estudo realizado na Colômbia23. Entreos seus entrevistados, alguns viram o toque retal como uma violação e humilhação a ponto de ser considerado a pior coisa que a eles aconteceram.

Outro sentido atribuído ao toque retal vincula-se à possibilidade de haver excitação. O corrida a excitação, indicada pela er eção do pênis, surgeo grande medo de pensar que o médico pode achar que o homem está gostando de ser tocado e isso pode colocar em risco a sua masculinidade:

Eu acho que existe um medo muito grande da excitação. D o excitar-se com isso ede isso poder ser mostrado para o outro, justamentea zona anal, éo grandetemor do homem, poder ter a possibilidade de sentir algum tipo de prazer nessa área ou de poder pelo menos sentir essa área, é um grande risco. ( $M$ arcos).

Em relação à possi bilidade de ter uma ereção com o toque, Gomes ${ }^{26}$ observa que "no imaginário, a ereção pode estar associada tão fortemente ao prazer que não se consegue imaginá-la como uma reação fisiológica".

Junto à possibilidade de se excitar por conta do toque, há também, no senso comum, como diz um dos nossos entrevistados, "determinado tipo de piada [que diz que] se o cara gostar do toque e aí [risos] fica viciado (M iguel).

Tanto ter ereção por conta de ser tocado por outro homem numa parte interdita, como gostar e ficar excitado, a partir do toque, são sentidos dissonantes com o modelo hegemônico de masculinidade. Assim, o toque retal pode ser visto como algo que conspira contra esse modelo.

A experiência deter sido penetrado pelo dedo, com fins de detecção precoce, foi diferenciada nos dois grupos. No Grupo I (homens com baixa ou nenhuma escolaridade), apenas um entrevistado mencionou ter feito esse exame esua experiência 
aponta para uma violação simbólica de sua masculinidade: "Eu [me] senti rebaixado com aquilo que ele [o médico] fez" (Américo).

Entre os entrevistados de baixa ou nenhuma escolaridade, a resistência ao exameé maior. N ão só pelo fato deapenasum deles ter feito o exame, mas também pelo fato de não terem grandes informações relativas ao exame. M as os homens debaixa ou nenhuma escolaridadetambém abordam a importância do exame detoque retal, apesar de não saberem explicar como ele se processa e de não terem, em sua grande maioria, realizado o exame.

Já o Grupo II (composto pelos sujeitos de nível superior) parece tolerar mais o fato de ter querealizar o exame detoque retal. Tanto équea maioria dos entrevistados já havia realizado o exame.

Se tivesse outra forma seria melhor, porque é uma coisa meio constrangedora. A primeira vez que eu fiz, cara, eu sai dali meio, me achando assim, puta que pariu [risos], uma coisa terrível. ( $M$ arcelo)

Eu já tive que fazer, doeu pra cacete [foi] uma sensação desagradabilíssima. M as não tenho trauma. (Mário)

É uma coisa meio constrangedora, mas não chega a ser o fim do mundo. ( $M$ arcelo)

Eu me senti bem, sem nenhum trauma, nem nada. (M ateus)

$\mathrm{N}$ ão, não vejo problema aténo sentido dequea masculinidade está muito calçada na visão do outro, sobre você, do que basicamentena sua. Eu não vejo o exame do toque retal como uma ofensa ou uma desconstrução daquela sexualidade. (M iguel)

Essas falas nos apontam que existem diferentes formas de se subjetivar o exame em questão. Segundo elas, o exame, de um lado, pode suscitar constrangimento, dor (física e simbólica) e, de outro, pode ser superado. Revela-nos também que, ainda que possa ser visto, em princípio, como uma violação da masculinidadepelo senso comum, ele pode não ser percebido dessa forma por determinados homens. M as, para alguns homens, se houvesse uma outra forma de exame seria melhor. Em outras palavras, o fato de ser examinado pelo toque retal porque se tem consciência de que deve ser feito tal exame não torna o procedimento menos constrangedor.

\section{À guisa de conclusão}

Como vimos, os dois grupos de homens estudados, em determinados momentos, se diferenciaram em suas falas e, em outros, se encontraram em sentidos partilhados, independentemente do seu grau de escolaridade.

Os homens com nível superior visivelmente apontaram para uma atitude maior de adesão ao toque retal, mesmo para aqueles que não 0 realizaram. Comparando-os com os do grupo de menor escolaridade, eles não só realizaram mais tal exame como também trouxeram uma maior crítica em relação ao fato de o modelo hegemônico de masculinidade influenciar a não busca deum diagnóstico precoce de câncer prostático. Em conseqüência disso, demonstraram maior poder de ressignificação do exame, apontando para a possibilidade de se aceitar um mal menor (toque retal) em prol de um bem maior (prevenir-se contra o câncer prostático).

Junto ao maior grau de escolaridade, não podemos desconsiderar que o fato do Grupo II ter maior facilidade deacessar os serviços de saúde, tanto pelo seu maior nível econômico como pelas suas jornadas de trabalho mais flexíveis, pode ter tido influência em sua atitude de maior adesão ao exame em questão. Assim, pelo fato de freqüentarem mais serviços de saúde, podem ser mais estimulados a buscarem medidas de prevenção em geral, incluindo as do câncer de próstata.

Por outro lado, os homens, independente do seu grau de escolaridade, partilharam de sentidos comuns que são construídos por influência do imaginário social. Seguindo esse raciocínio, observamos que 0 exame de toque retal, para ambos os grupos, pode suscitar interdições, violações e excitação, quase sempre associada ao desejo. Esses elementos suscitados mexem com o que se entende comumente por ser homem, como ser que não tem determinadas partes do seu corpo tocadas, não é penetrado e tem o controle de seu desejo. Nesse sentido, o toque retal não toca apenas a próstata, mas também toca na masculinidade, podendo arranhá-la.

Levar em conta as possíveis arranhaduras da masculinidade não significa desconsiderar a possibilidade de que tal exame possa ser subjetivado 
tanto pelos médicos como pelos homens em geral, fazendo com que tal medida seja percebida e vivenciada de forma diferenciada. Isso significa que não podemos projetar para todos os homens os medos presentes no imaginário social, nem tampouco reificá-los, como barreiras cristalizadas e intransponíveis.

Além dos aspectos simbólicos que podem estar relacionados com a resistência ao toqueretal, como detecção precoce do câncer prostático, não podemos desconsiderar outros aspectos de ordem estrutural que, direta ou indiretamente, também comprometem a realização detal detecção. Caminhando nessa direção, observamos que, de um lado, a insuficiência de serviços de urologia na rede pública de saúdee, de outro, a dificuldade por parte dos serviços de lidarem com as demandas do masculino são fatores que podem também fortalecer a resistência masculina à pre venção do câncer de próstata.

A partir dessa perspectiva, concluímos que, para a compreensão e problematização das questões sobrea prevenção do câncer prostático, através do toque retal, em específico, eas relacionadas ao cuidar de si masculino, em geral, se faz necessário levar em consideração os aspectos estruturais e simbólicos que perpassam tais questões.

\section{Colaboradores}

R Gomes coordenou a pesquisa e participou da coleta e análise dos dados, bem como da redação final do trabalho. EF Nascimento, LE Rebelo e FC Araújo participaram da análise dos dados da pesquisa e da redação final do trabalho.

\section{Agradecimentos}

Agradecemos 0 apoio do Conselho $\mathrm{N}$ acional de Desenvolvimento Científico e Tecnológico (CNPq), que proporcionou o desenvolvimento da pesquisa intitulada "A construção da masculinidade como um fator impeditivo do cuidar de si", que gerou este artigo. 


\section{Referências}

1. Instituto Nacional de Câncer . Síntese de resultados e comentários [texto na Internet], 2005. [acessado 2005 Out 30]. [cerca de 5 p.]. Disponível em: http:// www.inca.gov.br/estimativa/2005.

2. Sociedade Brasileira de U rologia (SBU). [site na Internet], 2005. [acessado 2005 Ago 9]. Disponível em: http://www.sbu.org.br

3. M iranda PC, Côrtes MCJW, M artins ME, Chaves PC, Santarosa RC. Práticas de diagnóstico precoce de câncer de próstata entre professores da Faculdade de Medicina - UFM G. Rev Assoc M ed Bras 2004; 50(3):272-275.

4. Nascimento MR. Câncer de próstata e masculinidade: motivações e barreiras para a realização do diagnóstico precoce da doença. [texto na Internet] 2005. [acessado 2005 Out 30] [cerca de 24 p.]. Disponível em: http://www.abesp.nepo.unicamp.br

5. Instituto Nacional de Câncer. Programa Nacional de Controle do Câncer da Próstata: documento de consenso. Rio de Janeiro; INCA; 2002.

6. Sociedade Brasileira de U rologia. Doenças da próstata: vença o tabu. Rio de Janeiro: Elsevier/Sociedade Brasileira de U rologia; 2003.

7. Varzin CAB, Srulzon GB, Cortado PLM, Netto Jr NR. Importância do toque retal e PSA no diagnóstico precoce do câncer da próstata. Rev Brasileira de M edicina [periódico na Internet] 2004. [acessado 2006 M ai 22] [cerca de 5 p.]. Disponível em: http:/ /www.cibersaude.com.br

8. Walsh PC, Worthington JF. Doença da próstata: um guia para os homens e para as mulheres que os amam. São Paulo: Martins Fontes; 1998.

9. Shimizu H. PSA em xeque. [texto na Internet] 2004 [acessado 2005 Out 30] [cerca de 3p.]. Disponível em: http://www.agencia.fapesp.br

10. Gomes R, Skaba MNVF, Vieira RJS. Reinventando a vida: proposta para uma abordagem sócio-antropológica do câncer de mama feminina. Cad Saúde Pública 2002; 18(Supl 1):197-204.

11. Oliveira PP. A construção social da masculinidade. Belo Horizonte: Editora UFM G; 2004.

12. Cecchetto FR. Violência e estilos de masculinidade. Rio de Janeiro: FGV Editora; 2004.

13. Denzin NK, Lincoln YS. Introduction: the discipline and practice of qualitative research. In: Denzin NK, Lincoln YS, editors. Handbook of qualitative research. London: Sage; 2000. p. 1-29.

14. Deslandes SF, Gomes R. A pesquisa qualitativa em serviços de saúde: notas teóricas. In: Bosi MLM, Mercado FJ, organizadores. Pesquisa qualitativa de serviços de saúde. Petrópolis: Vozes; 2004. p. 99-120.
15. M inayo M CS. Hermenêutica-dialética como caminho do pensamento social. In: M inayo MCS, Deslandes SF, organizadoras. Caminhos do pensamento: epistemologia e método. Rio de Janeiro: Fiocruz; 2002. p. 83-107.

16. Vaitsman J. Flexíveis e plurais: identidade, casamento e família em circunstâncias pós-modernas. Rio de Janeiro: Rocco; 1994.

17. Velho G. Individualismo e cultura. Rio de Janeiro: Zahar; 1981.

18. M inayo M CS. 0 desafio do conhecimento: pesquisa qualitativa em saúde. São Paulo: Hucitec; Rio de Janeiro: Abrasco; 2002.

19. Gomes R, Souza ER, M inayo M CS, Silva CFR. Organização, processamento, análise e interpretação de dados: o desafio da triangulação. In: M inayo MCS, Assis SG, Souza ER, organizadoras. Avaliação por triangulação de métodos: abordagem de programas sociais. Rio de Janeiro: Fiocruz; 2005. p. 185-221.

20. Courtenay WH. Constructions of masculinity and their influence on men's well-being: a theory of gender and health. Social science $\&$ medicine 2000; 50:1385-1401.

21. Hardy E, Jiménez AL. Políticas y estrategias en saIud pública. Rev Cubana Salud Publica 2001; 27(2):77-88.

22. Lucumí-Cuesta DI, Cabrera-Arana GA. Creencias de hombres de Cali, Colombia, sobre el examen digital rectal: hallazgos de un estudio exploratorio. Cad Saúde Pública 2005; 21(Supl 5):1491-1498.

23. Lucumí-Cuesta DI, Cabrera-Arana GA. Creencias sobre examen digital rectal como tamiz para cáncer en la próstata: hallazgos cualitativos de un estudio en Cali. Colomb Med 2003; 34:111-118.

24. Petersen A. Unmasking the masculine: 'men' and 'identity' in a skeptical age. London: Sage Publication; 1998.

25. Damatta R. Tem pente aí? In: Caldas $D$, organizador. Homens. São Paulo: SENAC; 1997. p. 31-49.

26. Gomes R. Sexualidade masculina e saúde do homem: proposta para uma discussão. Cienc Saude Colet 2003; 8(3):825-829.

Artigo apresentado em 29/06/2006

Aprovado em 13/11/2006

Versão final apresentada em 23/11/2006 